\title{
O SOL DE BALADA DE AMOR AO VENTO
}

Julian Bohrz ${ }^{1}$

Anselmo Perez Alós

RESUMO: Neste trabalho, pretende-se analisar o valor simbólico do elemento espacial sol no romance Balada de Amor ao Vento, de Paulina Chiziane. Intenciona-se compreender como, no romance, a noção ocidental do símbolo referido é desconstruída a fim de edificar um arcabouço simbólico com raízes africanas, capaz de produzir reflexões acerca da identidade, da emancipação e da afirmação da nação moçambicana por meio do possibilitado pelas especificidades do texto literário.

PALAVRAS-CHAVE: Identidade; símbolo; Paulina Chiziane; Balada de amor ao vento; Moçambique

ABSTRACT: In this paper, we intend to analyze the symbolic value of the sun in the novel Balada de Amor ao Vento, by Paulina Chiziane. It intends to understand how, in the novel, the Western notion of the symbol is deconstructed in order to construct a symbolic framework with African roots, being able to produce reflections about identity, empowerment and affirmation of the Mozambican nation.

KEYWORDS: Identity; symbol; Paulina Chiziane; Balada de amor ao vento; Mozambique.

\section{INTRODUÇÃO}

O romance Balada de Amor ao Vento, de Paulina Chiziane, trata dos eventos marcantes da vida da narradora Sarnau. A protagonista narra suas próprias lembranças, dos tempos de pobreza na tribo, do relacionamento com Mwando, do período em que foi rainha, porém não se mantém distanciada dos fatos narrados; pelo contrário, contamina-se com o ato de rememorar ao ponto de subverter os limites entre passado e presente. O passado, então, surge abrupto, profundo, revelador, fazendo com que o tempo, na narrativa, sirva não

\footnotetext{
${ }^{1}$ Graduando em Letras Bacharelado - Português/Literaturas pela Universidade Federal de Santa Maria (UFSM). Orientador: Anselmo Péres Alós. E-mail: julian.bohrz@hotmail.com.

2 Doutor em Literatura Comparada pela Universidade Federal do Rio Grande do Sul. Professor Adjunto no Departamento de Letras Vernáculas da UFSM. Professor do Programa de Pós-Graduação em Letras, na mesma instituição.
} 
somente para inserir em uma época os eventos narrados, mas, principalmente, para catalisar a narração.

Os eventos narrados são eivados por elementos mágicos, ou que soam mágicos pelo choque entre culturas (possível, talvez até provável, cultura ocidental do leitor versus cultura moçambicana). Trata-se de reis, feiticeiros, espíritos, mas isso não é apresentado através do viés da peculiaridade ou do fantasioso; pelo contrário, é narrado de maneira natural, porque a narradora está completamente envolvida com os fatos.

Ademais, as descrições do espaço natural africano, além de belas, são fundamentais para a compreensão dos sentidos mais subjacentes ao romance. Assim como os africanos valorizam a beleza e o poder intuitivo da natureza, a categoria espaço, no romance, é valorizada.

Em Balada de Amor ao Vento, o símbolo Sol, além de essencial para fundamentar o texto, na medida em que indica as passagens do tempo cronológico, também cria a ambientação e caracteriza as personagens, sobretudo a protagonista Sarnau e suas variações de humor. Entretanto, além dessa função básica, a simbologia do sol aponta também para reflexões metaficcionais e, ainda, para a necessidade da criação de uma identidade nacional baseada em uma revisão e retomada de elementos próprios da cultura moçambicana.

Portanto, justifica-se este trabalho, primeiramente pelo valor conferido na narrativa ao elemento Sol, que indica desde ambientação até reflexões críticas. Em segundo lugar, a relevância desta pesquisa assenta-se na necessidade de se observar como são organizadas, tendo em vista as possibilidades levantadas pela imagem e pelo símbolo em um texto literário, as reflexões acerca da construção de uma identidade nacional baseada em aparato cultural africano e não baseada na mera absorção e aplicação do imaginário ocidental.

\section{SÍMBOLO, ARQUÉTIPO, ESQUEMA}

$\mathrm{Na}$ tarefa de interpretar os indícios simbólicos de um texto literário, algumas questões acabam impondo presença, obrigando, desse modo, o crítico a encontrar respostas para organizar e ordenar o conhecimento 
apropriado para auxiliá-lo em suas análises. Todavia, ao lidar com termos como "imagem" e "símbolo", o pensamento racional tende a escrupulosamente hesitar em barreiras que se impõem à margem do rigor de uma sistematização acadêmica. Por isso, como afirma Bachelard (1998) em A Poética do Espaço, o estudo científico das imagens e símbolos poéticos acaba dialogando diretamente com dualidades não contempladas pelo pensamento científico, como alma - para o autor referido seria o resultado assistemático da inspiração subjetiva - e espírito - o trabalho árduo de adquirir, sistematizar e produzir conhecimento -

A imagem poética, de acordo com Bachelard (1998), seria lida e produzida sob os auspícios da alma, não sendo, então, passível de rigorosa sistematização. Desse modo, para o autor, apenas a fenomenologia seria capaz de apreender a amplitude e a lógica própria das imagens poéticas:

\footnotetext{
Percebemos então que essa transubjetividade da imagem não podia ser compreendida, em sua essência, apenas pelos hábitos das referências objetivas. Só a fenomenologia - isto é, a consideração do início da imagem numa consciência individual - pode ajudar-nos a reconstituir a subjetividade das imagens e a medir a amplitude, a força, o sentido da transubjetividade da imagem. [...] A imagem poética é, com efeito, essencialmente variacional. Não é, como o conceito, constitutiva. Sem dúvida, isolar a ação mutante da imaginação poética nos detalhes das variações das imagens é tarefa árdua, conquanto monótona. (Bachelard, 1988, p. 3-4)
}

Assim, analisar a imagem através de pressupostos fenomenológicos, respeitando sua essência peculiar, tendo em vista a transitoriedade das amarras que a ligam à realidade, é fundamental para uma análise eficaz do símbolo. Para Bachelard (1998), conferir um tratamento fenomenológico à imagem, que evoca uma "consciência ingênua", não se atendo, portanto, apenas aos pressupostos do pensamento racional - sempre organizado em torno de pensamentos interligados -, é benéfico, porque pode produzir resultados simples e precisos.

Para Duran (2002), em As Estruturas Antropológicas do Imaginário, Sartre, em L'imaginaire, ao preconizar o método fenomenológico para a análise de imagens, abriu caminho para análises do fenômeno do imaginário sem vínculo efetivo com qualquer ilusão de imanência. Sartre teria, então, acertado ao afirmar que, além de espontânea, a imagem é uma consciência, logo, 
transcendente; porém, teria soado equivocado ao reduzir a imagem ao que chamou de sua "pobreza essencial", a qual seria fomentadora de erros, afastando-se nocivamente do conhecimento verdadeiro.

Opondo-se à fenomenologia reducionista de Sartre e assumindo o caráter não apenas científico (mas não nocivo) da imagem, Duran (2002) propõe que esta seja estudada pelo que representa em si, pois "é ela mesma portadora de um sentido que não deve ser procurado fora da significação imaginária. O sentido figurado é, afinal de contas, o único significativo." (DURAN, 1998, p. 29). Entretanto, apesar de rechaçar uma sistematização científica e/ou meramente psicológica para a análise da imagem, procura, ao lidar com imagem e símbolo, reforços na realidade exterior, na psicanálise e no conhecimento científico.

Assim, com intuito de caracterizar racionalmente o símbolo, Duran (2002) utiliza as noções de esquema e arquétipo. O esquema seria a condição factiva e não substanciada do imaginário, algo como o esboço da imaginação, que não pode ser ordenado logicamente apesar de já possuir representação concreta. O arquétipo, por outro lado, seria a substantificação do esquema, o mediador entre esquemas subjetivos e imagens fornecidas pela natureza. Baseado na lógica de esquemas e arquétipos, porém a ultrapassando por seguir a uma lógica própria, o símbolo é considerado polivalente, enquanto o arquétipo seria universal: a roda seria o grande arquétipo do esquema ciclicidade, porém a serpente seria um símbolo de tal ciclicidade. Desse modo, o símbolo levaria em conta esquema, arquétipo e contexto situacional, histórico, cultural, linguístico.

\section{SOL: VALOR SIMBÓLICO}

O acuro necessário para analisar as imagens de um texto literário produz a necessidade de se atentar ao valor simbólico presente na figura do Sol. Duran (2002), ao produzir sua classificação de imagens e símbolos, divideos em duas categorias: o regime diurno das imagens e o regime noturno. Todo símbolo ligado à ideia de luz, figurando com central importância os solares, símbolos masculinos, implicariam a contrapartida, um símbolo ligado à ideia de 
noite, como a lua, símbolo feminino. É por isso que, em Balada de Amor ao Vento, por exemplo, o Sol aparece em momentos de paz, alegria, tranquilidade, mancomunado com a clareza de uma natureza pacificadora, representando o lado bom de morar em África, em oposição ao consequente regime noturno, representado pela noite e por uma natureza mórbida, hienas, serpentes, ervas daninhas e muita escuridão, que aparecem nos momentos de desespero, ódio, tristeza e desencontros amorosos.

De acordo ainda com Duran (2002), o sol, além de representar uma imagem pacificadora, possui muitas outras filiações simbólicas: $O$ imaginário levantado pelo matiz dourado, representante da virtude; a ideia de liberdade, levantada pela simbologia egípcia que faz analogia do sol ascendente com o pássaro; a visão indutora de clarividência, levantada pelos povos fueguinos, bushimanes e samoiedos de que o Sol é o olho divino; a associação, levantada por egípcios e pela simbologia cristã, da luz do sol com o poder das palavras; e, por fim, a visão de retidão moral, levantada pela própria retidão da luz do sol.

Pierre Brunel (2000), no Dicionário de Mitos Literários, organiza a profícua ligação entre sombras e luz na literatura através do exame da figura de Apolo.

\footnotetext{
O deus é chamado Lukeios, adjetivo que os estudiosos ligaram, e por vezes ainda ligam, a lukê, luz. Esta etimologia combina bem com o epíteto mais conhecido de Apolo, Phoibos, o "claro", o "brilhante", o "puro", que encontramos nos primeiros versos de Homero e Hesíodo, preparando a associação entre Hélio e Apolo [...]. Esta associação é afirmada durante a primeira metade do século V nas Bassáridas de Ésquilo, onde Orfeu declara que o sol também é chamado Apolo. (BRUNEL, 2000, p. 72).
}

Contudo, apesar de símbolo máximo da clareza e pureza, Apolo possui como qualificativo a escuridão, a sombra, o oblíquo, ideia inerente ao epíteto Loxias (BRUNEL, 2000, p. 74). Por isso, é importante para este trabalho, além de manter o foco na análise da simbologia do Sol e sua função na narrativa, ter em mente a forma com que a convencional oposição sombras e luz, iniciada em literatura pela figura de Apolo, é assimilada, alimentada com novos aspectos e mesmo transfigurada em Balada de Amor ao Vento. 


\section{A PERSONAGEM SARNAU E SEUS CONFLITOS, UM POUCO DE SOL E O REGIME DE IMAGENS}

Em Balada de Amor ao Vento, Sarnau, a narradora protagonista, é uma moça simples, que se apaixona por Mwando (um homem cristão que a abandona grávida), depois tenta se matar, não consegue se matar, e, enfim, é escolhida para ser mulher do rei por sua beleza, bondade e vontade de trabalhar.

Pensa-se a narrativa através das forças naturais. Nesse sentido, a relação entre símbolos do regime diurno de imagens e símbolos do regime noturno é fundamental. Quando as personagens estão felizes, o regime diurno de imagens aparece: o sol é caloroso, os animais são serelepes. Quando as personagens estão tristes, é o regime noturno de imagens que predomina: buscam a noite, os espaços escuros, aparecem, soturnos, animais como a serpente, a hiena. Além disso, quando a narradora está prestes a narrar um momento tenso, percebe-se que a natureza acompanha essa tensão. Isso ocorre porque a natureza é muita valorizada naquela cultura, ao ponto de, inclusive, funcionar como moeda (o contrato de casamento da personagem, por exemplo, está assentado na seguinte troca: o rei casa com Sarnau e em troca oferece algumas vacas para a família da narradora).

Ademais, às vezes, a natureza acaba funcionando como um "elemento prolépsico": no início de cada capítulo há uma apresentação da natureza, que acaba indiciando o que vai ser narrado ao longo do capitulo. Se aparecem mais elementos do regime noturno de imagens, haverá uma narração de eventos complicados da vida de Sarnau; em compensação, se aparecem mais elementos do regime diurno de imagens, um leitor desconfiado perceberá que serão narrados fatos alegres da vida da personagem. Funcionam da mesma forma as personagens curandeiros-profetas, que descobrem coisas sobre 0 futuro, como a curandeira e seus defuntos que preveem a morte de Sarnau em um lugar distante. Essa informação é de extrema importância na narrativa, pois, de posse de seu destino último, a narradora não se preocupa em se embrenhar em alguns perigos. Portanto, entende-se que o valor subjacente das coisas é de extrema importância para a cultura que está sendo apresentada no texto e, consequentemente, para o romance. 
Sarnau é uma personagem de alta complexidade, uma vez que, ao longo da narrativa, o narratário entra em contato com diversas Sarnaus. A primeira mudança na personalidade da personagem está ligada à beleza cintilante e inebriante do poder. A personagem aparece um pouco deturpada pelo poder logo depois do casamento, querendo adereços, desejando matar as sogras, esquecendo-se por breves instantes da vida pretérita repleta de sofrimentos:

\begin{abstract}
Nunca sonhei em ser a primeira esposa do herdeiro, mas agora só penso em ser rainha. Cada vez que me aproximo da velha, excito-me, e desejo ardentemente que sua morte seja breve para herdar os grandes braceletes de ouro que ela usa nos braços e nos pés. O poder é como vinho. No princípio confunde, transtorna, quase que amarga, pouco depois agrada e, no fim, embriaga" (CHIZIANE, 2007, p. 50).
\end{abstract}

Depois de alguns anos se passarem, no entanto, Sarnau já se apresenta como odiando sua vida de rainha, odiando o poder, odiando até as próprias filhas. É então que se reencontra com Mwando e suas esperanças de amor renascem. Mwando funciona, então, como elemento de caracterização indireta da personagem, como se nota no seguinte excerto: "Aqui chamam-te rainha, mas rainha de que? Tens uma falsa fortuna porque nada do que dizes ter te pertence, não tens amor, nem felicidade, nem vida. Vem, Sarnau, que a felicidade nos espera do outro lado do mar" (CHIZIANE, 2007, p. 97)

Entretanto, mesmo depois de fugir com Mwando, a proposta de felicidade e amor não se concretizou. Sarnau é novamente abandonada, depois reencontra-se com Mwando, e, aparentemente, é abandonada de novo. Portanto, conclui-se que o amor das personagens é realmente como o vento, que passa e leva tudo consigo. Sarnau, visivelmente, não nasceu para ser feliz, para sentir a plenitude do amor.

No final, no novo "passado presentificado", percebe-se que, mesmo depois de muitos anos, a narradora ainda confere bastante atenção aos problemas do seu passado, às lembranças, à vida com o rei e esposas, filhos e Mwando, ao abandono, à violência. A narradora demonstra que o passado provocou fortes consequências no presente, pois, enquanto narra os fatos/pensamentos da sua vida como vendedora de legumes no "presente", ainda rememora, durante essa mesma narração, os eventos trágicos do 
passado (CHIZIANE, 2007, p. 136-137). Já ao fim do romance, Sarnau afirma estar tomada irremediavelmente pelo amor de Mwando, precisa do amor daquele homem para sobreviver, porém está "vencida e perdida" (CHIZIANE, 2007, p. 149).

O Sol, elemento fundamental em Balada de Amor ao Vento, constrói uma imagem paradisíaca de África, o que é reforçado pela constatação de que a narrativa lida com um imaginário adâmico. Portanto, o amor de Sarnau (por falta de termo mais adequado, "pagã") e Mwando (cristão) pode ser intenso e dilacerante como o vento, porém, é tão proibido quanto o amor de Adão e Eva e tão dual quanto a relação luz e sombras.

\section{SARNAU E O SOL OU SARNAU É O SOL?}

No romance, o símbolo Sol, além de essencial para fundamentar a base do texto, na medida em que indica as passagens do tempo cronológico, também cria ambientação e caracteriza as personagens, sobretudo Sarnau e suas variações de humor: "O sol está vermelho, rebola e joga às escondidas com os imbondeiros no interior da savana, ah, as mulheres são mesmo bisbilhoteiras, intriguistas, o sol já dormiu, a minha sogra ainda me fala de feitiços" (CHIZIANE, 2007, p. 47). Nesse trecho, o sol funciona tanto como ambientação, quanto como caracterizador da personagem, bem como para demarcar a passagem de tempo, indicando o sentimento de raiva e desprezo (sol vermelho) de Sarnau em relação ao engodo das outras mulheres (rebola e joga às escondidas). Depois, personificado ("o sol já dormiu", ou seja, já é noite), indica a passagem de tempo cronológico em oposição à passagem (lenta) do "tempo psicológico" ("e minha sogra ainda me fala de feitiços").

A primeira descrição física da personagem é fundamental, pois, além de aproximar a personagem com a simbologia inerente ao sol, produz uma dupla desconstrução: desconstrói a idealizada imagem monárquica ocidental e, também, descontrói o ideal de beleza ocidental. A narradora, aliás, brinca com a imaginação do leitor/narratário, ao afirmar que o leitor estaria imaginando uma esposa do futuro rei de "mãos suaves", "rosto clarinho", "lábios vermelhos" (CHIZIANE, 2007, p. 40), e, após, ressaltar que sua beleza era diferente 
porque sua cultura era diferente, afinal, "cada mundo tem sua beleza" (CHIZIANE, 2007, p. 41). Com isso, a narradora acaba fazendo a primeira e única descrição (possível de se extrair) de sua aparência física:

No campo é mais belo o rosto queimado de sol. São belas as pernas fortes e musculosas, os calcanhares rachados que galgam quilômetros para que em casa nunca falte água, nem milho nem lume. São mais belas as mãos calosas, os corpos que lutam ao lado do sol, do vento e da chuva para fazer da natureza o milagre de parir a felicidade e a fortuna (CHIZIANE, 2007, p. 41).

A ideia de beleza para a tribo de Sarnau, então, é produzida através da ideia de regime diurno de Duran, sugerido pela simbologia do sol, ressaltando o valor da paz, do equilíbrio e da perseverança como características básicas da beleza moçambicana.

Por outro lado, o regime noturno aparece constantemente no romance de Paulina Chiziane, geralmente sugerindo uma relação negativa de oposição à clareza positiva do regime diurno. Nesse sentido, a passagem seguinte é bastante ilustrativa:

O insólito acontece na floresta. Todos os seres escutaram os segredos da natureza e estão a operar maravilhas. As corujas cantam ao sol; os gatos pretos miam intensamente à lua cheia. Todas estas vozes unem-se no compasso do vento, que espalha pelo mundo uma mensagem de paz. Os leões e os vitelos, acasalados, rugem e mugem num coro de fraternidade. As hienas e as cabras abraçam-se, perdoam-se, reconciliam-se, as aves vestem plumagens coloridas. A serpente, junto ao ninho, fecha os olhos, discreta, não vá ela interromper os beijos dos pássaros que se amam, crescem e multiplicam. As ervas e as arvores acumulam-se num verde impar, cobrindo-se de flores. Em todo universo há um momento de reflexão, de paz e de confraternização: chegou a época do amor. (CHIZIANE, 2007, p. 19).

Como se percebe, essa descrição da floresta, além de antecipar o que será narrado no capítulo (o início do relacionamento amoroso de Sarnau e Mwando e, ao mesmo tempo, a primeira decepção deles imposta pelas barreiras que separam a cultura cristã da cultura tribal) é importante, uma vez que é análoga ao conceituado por Durand acerca dos regimes de imagens. Nesse excerto, é o regime diurno que prevalece, colocando sob seu jugo os próprios elementos pertencentes ao regime noturno: as corujas cantam ao sol, as hienas se abraçam às cabras e se vestem de plumas coloridas; a serpente 
prefere fechar os olhos e manter-se na escuridão; as árvores, inseridas no regime diurno, juntamente com as ervas, geralmente inseridas no noturno, crescem ambas proficuamente. Isso tudo indica que, apesar de o regime diurno vigorar, ou apesar de as alegrias vivificarem naquele momento, o regime noturno, ou as tristezas e os empecilhos, apesar de disfarçado, estava também presente.

Sendo assim, é possível afirmar que o regime noturno de imagens aparece nos momentos de tensão, tristeza e problemas na narrativa. Serve para ambientar a morte do rei, que ocorre durante a noite; serve para ambientar a expulsão de Mwando do convento, que só ocorre depois do pôr do sol (entretanto, ao pedir perdão e refletir sobre a vida, Mwando aproxima-se do candeeiro...); serve, enfim, para caracterizar Angola, terra de tristezas e degredo: "Em Angola há um pedaço de terra adubado de sangue. Por baixo de cada sombra reside o corpo de um preto anônimo, confirmam os mais velhos" (CHIZIANE, 2007, p. 125)" e "As pessoas quando vão para Angola, no navio, dão adeus à terra, à família, aos amigos e "ao sol que os confortara" (CHIZIANE, 2007, p. 115). Logo, as pessoas estão saindo de um espaço feliz, de sol caloroso e aconchegante, para um lugar pior, para Angola, "terra de degredo, cana e café" (CHIZIANE, 2007, p. 117), terra de trabalho forçado e não de conjunção com a natureza.

Sendo assim, o sol e o regime diurno de imagens aparecem na narrativa para caracterizar Moçambique e a alegria de estar ou ser moçambicano. O sol, então, funciona como o lado bom de estar em Moçambique e ser africano, a alegria da tribo, a beleza da natureza aos olhos de Sarnau, em oposição à escuridão que aparece nos momentos de tristeza, de "feiura", injustiça e infelicidade. Ora, o sol (e isso é perceptível observando brevemente alguns sites de turismo em Moçambique) é um dos chamarizes da terra, algo que caracteriza a região e aparece como atributo agradável do local. Na medida em que se louva, em que se apresenta a importância do sol na narrativa, acaba-se por louvar e apresentar a importância de Moçambique através da narrativa e desse sol.

A narradora não trata dos acontecimentos de maneira distanciada, pelo contrário, parece partir do ponto de vista da própria subjetividade; basta 
observar a reiteração de palavras como "sou", "sinto", "estou", "pensei", ao longo da narrativa. Na seguinte passagem, fica perceptível que a narradora relata seu casamento através do que observa "a partir de si", promovendo, desse modo, um olhar da realidade objetiva perpassado pelas suas impressões subjetivas:

Como estou bela, vestida de branco. Como é belo meu marido, trajado de preto. Este anel brilha no meu dedo como o sol. Como é emocionante essa melodia com que o povo nos saúda, e que sempre pensei que era dedicada aos anjos. Hoje sou lua, sou rainha, o mundo inteiro curva-se aos meus pés (CHIZIANE, 2007, p. 44).

É somente dessa maneira que o leitor toma contato com o casamento dela. O leitor tem de ir decodificando as pistas da linguagem para compreender que é do casamento que a narradora está tratando. Sarnau não diz: "Agora falarei sobre meu casamento", mas dá pistas: "como estou bela vestida de $\underline{\text { branco, }}$ este anel que brilha no meu dedo"), ora, a personagem está vestida com uma roupa de casamento, em seu anel paira um anel de casamento, logo, é de seu casamento que ela está a tratar.

Além disso, a relação entre sol e lua indica uma oposição não opositiva entre os regimes de imagens, isto é, a claridade e a luz parecem estar em contraponto, mas funcionam de modo conjunto, completando-se. Primeiro, nota-se que a personagem veste branco, indicando que ela tem mais filiação com o regime diurno, ou mesmo que as projeções de futuro baseadas no casamento eram boas. Entretanto, o marido veste preto, o que já poderia indiciar que o rei seria a escuridão para Sarnau. Ainda em relação a essa passagem, a personagem deixa claro que seu anel brilha como o sol, indicando a esperança em uma vida nova repleta de luminosidade.

Posteriormente, a personagem apresenta o outro lado do regime: Sarnau afirma-se como lua, sedutora, poderosa, rainha, aquela que tenta trazer luz à escuridão. Se a narradora não narra distanciada e assume por seguidas vezes o poder de trazer luz à escuridão que insiste em aparecer mesmo nos momentos de alegria, percebe-se que o papel da personagem, relacionado com o papel simbólico do Sol, pode ir além da mera narração de suas memórias. 


\section{CONSIDERAÇÕES FINAIS}

O elemento sol pode apontar para uma reflexão metaficcional. Sarnau, em vários momentos de sua narração, assimila o estatuto totalizante do sol para si própria ("Eu sou o sol"; "O sol brilhou em mim”...), indicando que a personagem se identifica completamente com a estrela central do Sistema Solar. Se o sol é o elemento máximo da narrativa, aquilo que permeia toda a narração, que influencia em todas as categorias narrativa, logo, o sol de Balada de Amor ao Vento é exatamente Sarnau, pois ela é a voz que narra, ela é quem permeia toda a narração, ela influencia em todas as categorias narrativas, ela, enfim, constrói e organiza o universo ficcional.

Destarte, é conveniente notar como a noção ocidental do sol como símbolo masculino é subvertida. Em Balada de Amor ao Vento, o Sol da narrativa é Sarnau, uma mulher que sofre por amor, luta contra o sistema machista e patriarcal instituído e questiona valores obsoletos de sua tribo. Ao assumir o estatuto simbólico totalizante do Sol para si, uma mulher moçambicana, a narradora desconstrói a visão masculinista desse símbolo, o que se relaciona com a tentativa da narradora-personagem de desconstruir 0 machismo patriarcal que era lugar comum em sua tribo. Subverter os arquétipos e esquemas do símbolo sol na narrativa é fundamental para, simbolicamente, indicar a necessidade de subverter os nocivos preconceitos e valores arcaicos da sociedade tribal apresentada no universo narrativo do romance.

A desconstrução do símbolo funciona também para ressaltar a necessidade de se criar uma identidade nacional moçambicana fundamentada no que há de específico nessa cultura e não na aplicação de aparatos conceituais, e mesmo simbólicos, da cultura ocidental. Desse modo, ao ressaltar a importância do sol para Moçambique e ao assumir a simbologia do sol para si, Sarnau acaba se transformando em uma espécie de símbolo de africanidade. A personagem sofre por amor, sofre por sua condição inferior em relação à tradição tribal, sofre pela oposição entre religião pagã e cristã, sofre por seus familiares, mas sempre reflete sobre como melhorar sua situação, sempre luta para alcançar seus objetivos, sem perder a alegria e vontade de 
viver. Nota-se, então, que Sarnau realmente carrega em si a simbologia inerente ao Sol e, se o sol é o representante maior de Moçambique, a personagem pode funcionar como uma representante mítica do país, representando o povo moçambicano, alegre mas sofredor, cheio de desejo de viver, crescer e batalhar por si e pelos outros.

\section{REFERÊNCIAS BIBLIOGRÁFICAS}

BACHELARD, Gaston. A poética do espaço. São Paulo: Martins Fontes, 1993.

BRUNEL, Pierre. Dicionário de mitos literários. Rio de Janeiro: José Olympio, 2000.

CHIZIANE, Paulina. Balada de amor ao vento. Lisboa: Editorial Caminho, 2003.

DURAND, Gilbert. As estruturas antropológicas do imaginário. São Paulo: Martins Fontes, 1997. 